\title{
Work Limitations and Productivity Loss Are Associated with Health-Related Quality of Life but Not with Clinical Severity in Patients with Psoriasis
}

\author{
Jochen M. Schmitt ${ }^{a, d}$ Daniel E. Ford ${ }^{a, b, c}$ \\ ${ }^{a}$ Department of Epidemiology, Johns Hopkins Bloomberg School of Public Health, and Departments of \\ ${ }^{b}$ Medicine and ${ }^{C}$ Psychiatry, Johns Hopkins University, Baltimore, Md., USA; ${ }^{d}$ Department of Dermatology, \\ University Hospital Carl Gustav Carus, Technical University Dresden, Dresden, Germany
}

\section{Key Words}

Absenteeism - Economic burden - Dermatology life quality index $\cdot$ Health economy $\cdot$ Presenteeism $\cdot$ Psoriasis ity loss by improving patients' quality of life. Savings from increased work productivity might offset comparatively high acquisition costs of biological agents.

Copyright $\odot 2006$ S. Karger AG, Basel

\section{Background}

Psoriasis is a frequent chronic inflammatory disease that primarily affects the skin. Currently incurable psoriasis can occur at any age, is equally distributed between men and women, and has a higher prevalence in Caucasians compared to African-Americans [1, 2]. Clinically, the severity of psoriasis is described by the intensity and extent of the psoriatic lesions. From the patients' perspective, however, the impact psoriasis has on their everyday physical, social and psychological-emotional functioning is most important [3-6].

The introduction of biological agents in the treatment of psoriasis offers patients new hope for safe and effective therapy [7-11]. Comparatively high acquisition costs of these new agents however evoked a debate about their appropriate use [12]. This is one reason why pharmacoeco-

\section{KARGER}

Fax +4161306 1234

E-Mail karger@karger.ch

www.karger.com (c) 2006 S. Karger AG, Base

$1018-8665 / 06 / 2132-0102 \$ 23.50 / 0$

Accessible online at:

www.karger.com/drm
Jochen Schmitt, MD, MPH, Department of Dermatology

University Hospital Carl Gustav Carus, Technical University Dresden

Fetscherstrasse 74, DE-01307 Dresden (Germany)

Tel. +49 351458 2497, Fax +49351458 5326

E-Mail jochen.schmitt@uniklinikum-dresden.de 
nomic analyses have recently gained more interest in the dermatological literature [13-18]. Guidelines for pharmacoeconomic studies recommend to use the societal perspective, which means that direct and indirect costs of disease need to be considered [19-22]. The direct costs are the cost for the intervention itself, e.g. drugs, physician visits and hospitalization cost. Related direct costs include expenditures on information material and transportation cost. In a recent study the annual direct cost of psoriasis treatment in the USA has been estimated to be about 650 million USD, more than half of which is spent on overthe-counter drugs [16]. Indirect costs are defined as opportunity cost of persons unable to work. These costs due to lost productivity include costs of absenteeism and presenteeism [23, 24]. 'Presenteeism' is defined as lost productivity because of illness or other medical conditions while on the job $[25,26]$. With estimated total costs of 150 billion USD per year in the USA, the total costs of presenteeism exceed those of absenteeism [25]. Although it is crucial to include the costs resulting from productivity loss in pharmacoeconomic evaluations, corresponding data for psoriasis patients have not been assessed yet.

Our aim was to estimate the cost of work productivity loss in patients with psoriasis. We were further interested in the association of productivity loss, health-related quality of life (HRQL) and clinical disease severity.

\section{Methods}

\section{Setting and Study Population}

The presented data were collected in the context of a larger cross-sectional study on the morbidity of psoriasis patients, which was conducted through the Internet between January and May 2005. Patients 18 years or older with self-reported psoriasis who accessed the Internet from the USA were eligible. The geographical identification of Internet users was inferred from the corresponding Internet protocol addresses. Recruitment included an advertisement at google.com that appeared on the screen when 'psoriasis' or related search terms were entered. The advertisement was 'Johns Hopkins Study. Psoriasis \& Quality of Life - 30-min questionnaire - get your report back'. After clicking the web-link of the advertisement, participants entered the interactive study Internet page.

Ethical approval from the Office for Research Subjects, Johns Hopkins Bloomberg School of Public Health, Baltimore, Md., was received prior to initiating the study. All participants provided informed consent before starting to answer the study questionnaires.

\section{Assessments}

Presenteeism, defined as lost productivity while on the job, was assessed using the output demands component of the Work Limitations Questionnaire (WLQ) [27]. The WLQ is a self-report in- strument with adequate psychometric properties (internal consistency, construct validity, reliability, accuracy) [26]. It measures the on-the-job impact of chronic conditions within the past 2 weeks and has already been applied in various psychiatric and rheumatological conditions [26, 28-31]. From the four WLQ domains (time, physical, output and mental-interpersonal demands) the output demands domain has the highest relative validity and has been shown to be the best predictor of productivity loss. The other WLQ scales each exhibit only half the predictive power of the output demands scale or less [27]. The output demands scale includes 5 items (handling the workload, finishing work on time, working fast enough, working without making mistakes, doing what one is capable of doing). Items are scored on a $0 \%$ (limited none of the time) to $100 \%$ (limited all of the time) scale. The total output demands score is the average item score. It indicates the percentage of time in the prior 2 weeks the respondent was limited performing output demands [27].

An advantage of the WLQ is that it has been validated against actual work productivity loss: for every $10 \%$ increase in the WLQ output demands scale, actual work productivity declined by approximately $4.5 \%$ [32]. This allowed us to approximate the economic impact of presenteeism due to psoriasis in the USA in terms of USD by applying the following formula:

mean total output demands score $\cdot 0.45 \% \cdot$ annual average income $\cdot$ prevalence $\cdot$ [US population age $18-65 \cdot$

(1 - unemployment rate)]

with:

- average annual income (2002): USD 36,764 [33]

- prevalence: $2.5 \%$ in Caucasians, $1.3 \%$ in African-Americans [2]; $\rightarrow$ weighted average [34] $=2.5 \cdot 86 \%+1.3 \cdot 14 \%=2.3 \%$

- US population aged 18-65 [34]: 174,243,050

- unemployment rate (our data used, see below): $16.3 \%$

The assumptions made for this estimation are discussed below.

To assess the time lost from work because of absences, participants were asked to indicate how many workdays they had missed fully and partly within the past 4 weeks due to health or medical care and how many workdays they missed due to other reasons. A full workday missed was given the value of 1 , a part day one of 0.5 [30]. The monetary economic impact of health-related absenteeism of persons with psoriasis in the USA was estimated by:

percent workdays missed due to medical reasons.

average annual income prevalence .

[US population age $18-65 \cdot(1-$ unemployment rate $)$.

We added the cost of presenteeism and the cost of absenteeism to estimate the total cost of health-related work productivity loss (HRWPL) in patients with psoriasis in the USA.

HRQL was assessed using the Dermatology Life Quality Index (DLQI), a widely used instrument with adequate psychometric properties (e.g. validity, reliability, sensitivity to change) [35-37]. It consists of 10 questions considering the following domains: symptoms and feelings, daily activities, leisure, work and school, personal relationships, and the effects of treatment on daily life.

The self-administered Psoriasis Area and Severity Index (SAPASI) is a patient-rated instrument with adequate psychometric properties to assess the objective clinical severity of psoriasis [38-42]. To be applicable in the Internet setting, the SAPASI 
was slightly modified (mSAPASI): as in the original version, patients rated the intensity of erythema, induration and scaliness on a $12-\mathrm{cm}$ visual analogue scale (VAS) [40]. For estimation of the involved body surface area (BSA), patients were informed that the area of their palmar hand equals roughly $1 \%$ of their BSA. Participants were then asked to estimate the percentage of their body covered with psoriatic plaques. As in the original PASI, the percent BSA involvement was recategorized into a semiquantitative score with 0 indicating no, $1=1-9 \%, 2=10-29 \%, 3=30-49 \%, 4=50-$ $69 \%, 5=70-89 \%$ and $6=90-100 \%$ BSA involvement [43].

The mSAPASI was calculated using the formula:

[(VAS erythema + VAS scaliness + VAS induration $) / 3] \cdot$

BSA score.

The mSAPASI score ranges from 0 to 72 with higher scores indicating higher objective disease severity. Severe psoriasis was defined as mSAPASI $>12$, a score between 7 and 12 as moderate psoriasis, and a score of less than 7 as mild psoriasis [44].

Information on sociodemographic characteristics included age, sex, ethnicity, annual household income, education level and average weekly worktime. Information on specific disease characteristics of psoriasis included diagnosis by physician, treatment within the past 14 days, joint involvement and presence/absence of facial lesions, genital lesions, hand involvement and feet involvement within the past 14 days. Participants were also asked to rate their overall health state on a 5-point Likert scale and to indicate if they were temporarily or permanently disabled.

To increase internal validity, participants were also asked to indicate whether they answered all questions honestly and whether they had completed the study questionnaire more than once. Participants indicating they did not answer honestly or were participating more than once were excluded from the analysis. The questionnaire was designed in a way that allowed proceeding to the next set of questions only if all previous questions had been answered. Therefore there were no missing data for our analysis.

Statistical Analysis

The $\chi^{2}$ test and Fisher's exact test were used to compare sociodemographic characteristics, disease characteristics and comorbidity of study participants by HRWPL (median defined as cutoff) [45]. Spearman correlation coefficients were calculated to describe the univariate association of HRWPL, DLQI and mSAPASI. Additionally, univariate and multivariate logistic regression analyses were performed to describe factors associated with HRWPL. The fit of the final multivariate model was assessed by Hosmer-Lemeshow's $\chi^{2}$ test [45].

The study web page was programmed in PERL 5. Javascript was used for real-time data analysis. The data were recorded in an SQL database and transferred to Stata statistical software 8.0 for Windows, which was then used to perform the statistical analysis [46].

\section{Results}

A total of 332 persons between the age of 18 and 65 started answering the questionnaires, 54 (16.3\%) of whom were currently unemployed. From the remaining 278 par- ticipants, 77 (27.7\%) dropped out before answering the WLQ. The following results are based on the 201 participants who completed the study.

The sample was in the majority female, predominately white, less than $50 \%$ had completed a college education and about $78 \%$ worked full-time. Almost all participants (96\%) had physician-diagnosed psoriasis, which was treated only topically in 59\%, systemically in about $19 \%$ and not at all in $22 \%$ of the study subjects. The mean clinical severity in terms of mSAPASI was $9.5( \pm 8.9)$ with about half of the patients being categorized as having mild and about $25 \%$ as having moderate or severe psoriasis. About $22 \%$ of patients reported presence of psoriatic arthritis, $48 \%$ lesions on their hands and $32 \%$ involvement of their face. The mean DLQI was 10.8 ( \pm 7.1 ); three quarters of the participants rated their health status as good, very good or excellent (table 1).

\section{Presenteeism and Absenteeism}

On average, participants had missed 6.6\% ( $\pm 15.4 \%$ ) of their working time within the past 4 weeks because of health problems. Absences due to reasons other than health accounted for $7.3 \%$ ( $\pm 16.1 \%$ ) of the working time. $34 \%$ of participants had missed at least 1 day of work, and $10 \%$ had missed 3 or more days of work within the past 4 weeks due to problems with their health. Assuming generalizability of these results, the annual cost of health-related absenteeism of psoriasis patients in the USA amounts to about USD 7,696,308,000. The mean WLQ output demands score was 16.8 ( \pm 20.1 ) reflecting a mean productivity loss because of presenteeism of $7.6 \%$ ( $\pm 9.1 \%)$, and an annual cost of about USD 8,862,415,000. Based on these numbers, the total HRWPL in psoriasis patients was calculated to amount to about USD 16,558,723,000.

\section{Factors Associated with HRWPL}

None of the sociodemographic characteristics assessed was significantly associated with HRWPL. Patients with physician-diagnosed psoriasis tended to have a higher HRWPL $(p=0.07)$. Among patients with a higher HRWPL, 57\% reported lesions on their hands compared to $39.6 \%$ of the subgroup with a lower HRWPL $(\mathrm{p}=0.01)$. Mild objective disease severity was associated with a lower likelihood of high HRWPL, whereas similar proportions were classified as having severe psoriasis in the high- and low-HRWPL groups (26 vs. 23.8\%; table 1). The correlation between mSAPASI and HRWPL was only weak $(\rho=0.22)$. Both psoriatic arthritis and disability were more frequent in the subgroup with a higher HRW$\mathrm{PL}$, but these associations were not statistically significant. 
Table 1. Comparison of sociodemographic characteristics, disease characteristics and comorbidity of study participants by productivity loss because of disease-related absences and presenteeism (productivity loss $\geq 7.3 \%$ vs. $<7.3 \% ; \mathrm{n}=201)$

\begin{tabular}{|c|c|c|c|c|c|}
\hline Variable & $\begin{array}{l}\text { Total } \\
(n=201)\end{array}$ & $\begin{array}{l}\text { Productivity } \\
\text { loss } \geq 7.3 \% \\
(\mathrm{n}=100)\end{array}$ & $\begin{array}{l}\text { Productivity } \\
\text { loss }<7.3 \% \\
(\mathrm{n}=101)\end{array}$ & $\chi^{2}$ & $\mathrm{p}$ value \\
\hline \multicolumn{6}{|l|}{ Sociodemographics } \\
\hline Gender, \% females & 61.2 & 64.0 & 58.4 & \multirow[t]{2}{*}{0.66} & \multirow[t]{2}{*}{0.42} \\
\hline Mean age, years & $42.7 \pm 11.5$ & & & & \\
\hline $18-25$ & 8.5 & 10.0 & 6.9 & \multirow{5}{*}{4.97} & \multirow{5}{*}{0.29} \\
\hline $26-35$ & 20.9 & 22.0 & 19.8 & & \\
\hline $36-45$ & 24.9 & 28.0 & 21.8 & & \\
\hline $46-55$ & 31.8 & 31.0 & 32.7 & & \\
\hline $56-65$ & 13.9 & 9.0 & 18.8 & & \\
\hline Race, \% white & 92.0 & 93.0 & 91.1 & 0.25 & 0.62 \\
\hline \multicolumn{6}{|l|}{ Annual household income } \\
\hline Less than 30,000 USD & 18.9 & 19.0 & 18.8 & \multirow{3}{*}{0.06} & \multirow{3}{*}{0.97} \\
\hline $30,000-60,000$ USD & 37.8 & 37.0 & 38.6 & & \\
\hline More than 60,000 USD & 43.3 & 44.0 & 42.6 & & \\
\hline \multicolumn{6}{|l|}{ Educational level } \\
\hline No degree & 6.5 & 6.0 & 6.9 & \multirow{3}{*}{0.07} & \multirow{3}{*}{0.97} \\
\hline Highschool & 46.8 & 47.0 & 46.5 & & \\
\hline College & 46.8 & 47.0 & 46.5 & & \\
\hline \multicolumn{6}{|l|}{ Weekly worktime } \\
\hline$<35 \mathrm{~h}$ & 21.9 & 23.0 & 20.8 & \multirow[t]{2}{*}{0.14} & \multirow[t]{2}{*}{0.71} \\
\hline$\geq 35 \mathrm{~h}$ & 78.1 & 77.0 & 79.2 & & \\
\hline \multicolumn{6}{|l|}{ Characteristics of psoriasis } \\
\hline Diagnosis by physician & 96.0 & 99.0 & 93.1 & - & 0.07 \\
\hline \multicolumn{6}{|l|}{ Treatment within the past 14 days } \\
\hline None & 21.9 & 18.0 & 25.7 & \multirow{3}{*}{3.57} & \multirow{3}{*}{0.17} \\
\hline Topical treatment & 58.7 & 58.0 & 59.4 & & \\
\hline Systemic/UV treatment & 19.4 & 24.0 & 14.9 & & \\
\hline Mean clinical severity (mSAPASI) & $9.5 \pm 8.9$ & & & \multirow{4}{*}{8.77} & \multirow{4}{*}{0.01} \\
\hline Mild (mSAPASI <7) & 50.2 & 41.0 & 59.4 & & \\
\hline Moderate (mSAPASI 7-12) & 24.9 & 33.0 & 16.8 & & \\
\hline Severe $($ mSAPASI $>12)$ & 24.9 & 26.0 & 23.8 & & \\
\hline Mean subjective severity (DLQI) & $10.8 \pm 7.1$ & & & & \\
\hline Low HRQL impairment (DLQI <6) & 27.4 & 13.0 & 41.6 & & \\
\hline Moderate HRQL impairment (DLQI 6-12) & 38.3 & 39.0 & 37.6 & 25.86 & $<0.01$ \\
\hline Severe HRQL impairment (DLQI >12) & 34.3 & 48.0 & 20.8 & & \\
\hline Psoriatic arthritis & 21.9 & 26.0 & 17.8 & 1.97 & 0.16 \\
\hline \multicolumn{6}{|l|}{ Psoriatic lesions at special locations (current) } \\
\hline Face & 32.3 & 35.0 & 39.7 & 0.64 & 0.42 \\
\hline Hands & 48.3 & 57.0 & 39.6 & 6.09 & 0.01 \\
\hline Feet & 38.3 & 44.0 & 32.7 & 2.73 & 0.10 \\
\hline Genital & 41.8 & 47.0 & 36.6 & 2.22 & 0.14 \\
\hline \multicolumn{6}{|l|}{ Comorbidity } \\
\hline \multicolumn{6}{|l|}{ Overall health state, including psoriasis } \\
\hline Poor & 3.0 & 5.0 & 1.0 & & \\
\hline Fair & 22.9 & 31.0 & 14.9 & - & $<0.01$ \\
\hline Good, very good, excellent & 74.1 & 64.0 & 84.2 & & \\
\hline Temporal/permanent disability & 4.5 & 7.0 & 2.0 & - & 0.10 \\
\hline
\end{tabular}

Apart from mean age, mean clinical severity and mean subjective severity, results are expressed as percentages. SD = Standard deviation; - = not applicable, Fisher's exact test performed. 
Table 2. Univariate logistic regression on productivity loss because of diseaserelated absences and presenteeism (productivity loss $\geq 7.3 \%$ vs. productivity loss $<7.3 \%$; $=201$ )

\begin{tabular}{lllr}
\hline Covariate & $\begin{array}{l}\text { Odds } \\
\text { ratio }\end{array}$ & $\begin{array}{l}\text { 95\% confidence } \\
\text { interval }\end{array}$ & p value \\
\hline $\begin{array}{l}\text { Clinical severity (mild: mSAPASI <7) } \\
\quad \text { Moderate to severe: (mSAPASI } \geq 7)\end{array}$ & 2.11 & $1.20-3.70$ & 0.009 \\
$\begin{array}{l}\text { Subjective severity (low: DLQI <6) } \\
\quad \text { Moderate HRQL impairment (DLQI 6-12) }\end{array}$ & 3.32 & $1.54-7.13$ & 0.002 \\
$\quad$ Severe HRQL impairment (DLQI >12) & 7.38 & $3.30-16.54$ & $<0.001$ \\
$\quad \begin{array}{l}\text { Psoriatic lesions at special locations (absent) } \\
\text { Face }\end{array}$ & 1.27 & $0.70-2.30$ & 0.423 \\
$\quad$ Hands & 2.02 & $1.15-3.55$ & 0.014 \\
$\quad$ Feet & 1.62 & $0.91-2.87$ & 0.100 \\
$\quad$ Genital & 1.53 & $0.87-2.69$ & 0.137 \\
Treatment within the past 14 days (none) & & & 0.351 \\
$\quad$ Topical treatment & 1.39 & $0.69-2.82$ & 0.063 \\
$\quad$ Systemic/UV treatment & 2.31 & $0.96-5.58$ & 0.004 \\
Overall health state (good, very good, excellent) & & & 0.087 \\
$\quad$ Fair & 2.74 & $1.37-5.51$ & 0.106 \\
$\quad$ Poor & 6.64 & $0.76-58.23$ & \\
Temporal/permanent disability (absent) & 3.73 & $0.75-18.39$ & \\
\hline
\end{tabular}

Reference groups are indicated in parentheses.

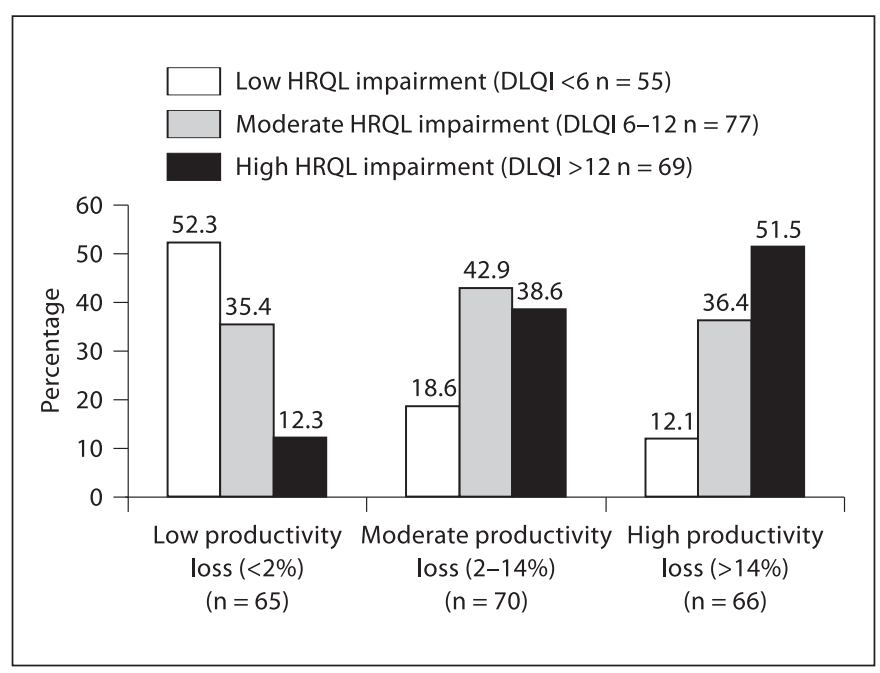

Fig. 1. Health-related productivity loss for participants by HRQL impairment $(\mathrm{n}=201)$. $\mathrm{p}$ value for trend $<0.001$.

Self-classification of the health status as 'poor' or 'fair' was a positive predictor for a higher HRWPL $(p<0.01$; table 1).

A clear dose-response relationship between HRWPL and HRQL impairment was observed ( $\mathrm{p}$ values for trend $<0.001$ for all strata). More than $50 \%$ of the participants in the highest HRWPL tertile had a DLQI of more than 12, whereas more than half of the patients with an HRWPL of less than 2\% were also in the lowest DLQI group (table 1, fig. 1). The correlation between DLQI and HRWPL was also highly statistically significant $(\mathrm{p}<0.001$; $\rho=0.47)$.

Table 2 summarizes results from the univariate logistic regression analysis. Compared to the subgroup with low HRQL impairment the odds of a higher HRWPL was 3.32 for patients with moderate and 7.38 for patients with high HRQL impairment ( $\mathrm{p}<0.01$ for each). Additional statistically significant predictors for a high HRWPL included moderate or severe objective disease severity (odds ratio $=2.11 ; \mathrm{p}=0.01$ ) and psoriatic lesions on the hands (odds ratio $=2.02 ; p=0.01$; table 2 ). In the final multi-adjusted logistic regression model predicting HRWPL, only HRQL impairment (DLQI) and temporal/ permanent disability were independently associated with HRWPL (table 3). Age, gender and annual household income, weekly working time, objective disease severity (mSAPASI) and hand involvement were included in the final model due to results from the univariate analysis and considerations regarding potential confounding. The adjusted odds ratio of high HRWPL for participants with a DLQI score of 12 or more compared to those with a lower HRQL impairment (DLQI <6) was 7.81 $(\mathrm{p}<0.01$; table 3$)$. 
Table 3. Multi-adjusted ${ }^{\mathrm{a}}$ logistic regression on productivity loss because of diseaserelated absences and presenteeism (productivity loss $\geq 7.3 \%$ vs. productivity loss $<7.3 \%$; $=201$ )

\begin{tabular}{lllr}
\hline Covariate & $\begin{array}{l}\text { Odds } \\
\text { ratio }\end{array}$ & $\begin{array}{l}\text { 95\% confidence } \\
\text { interval }\end{array}$ & p value \\
\hline Impairment of HRQL & & & \\
$\quad$ Low (DLQI <6) & reference & \\
$\quad$ Moderate (DLQI 6-12) & 4.48 & $1.89-10.65$ & 0.001 \\
High (DLQI >12) & 7.81 & $2.91-21.00$ & $<0.001$ \\
Objective severity of psoriasis & reference & \\
$\quad$ Mild (mSAPASI <7) & 1.05 & $0.51-2.14$ & 0.895 \\
$\quad$ Moderate to severe (mSAPASI $\geq 7)$ & 1.58 & $0.83-3.03$ & 0.166 \\
Presence of psoriatic lesions on hands (current) & 12.69 & $1.89-84.99$ & 0.009 \\
Temporal/permanent disability & $5.99(\mathrm{p}=0.42)$ & \\
\hline Hosmer-Lemeshow $\chi^{2}$ & \multicolumn{2}{l}{} \\
\hline
\end{tabular}

${ }^{a}$ Adjusted for age, gender, annual household income and weekly working time.

\section{Discussion}

Not unexpectedly, we found evidence of substantial work productivity loss in patients with psoriasis. Indirect costs due to decreased productivity while on the job and due to health-related absenteeism seem to substantially exceed the direct cost of psoriasis treatment [16].

There is good reason to believe that intervention can reduce HRWPL primarily by improving the patients' HRQL. Positive impact on HRQL has recently been reported for infliximab, etanercept, alefacept, efalizumab and cyclosporine [47-52]. Work productivity has not been included as an outcome in psoriasis studies yet. In patients with rheumatoid arthritis, Yelin et al. [53] found evidence of improved work productivity and employment status after etanercept treatment. Contrary to current guidelines on pharmacoeconomic analyses, published cost-effectiveness studies on antipsoriatic agents do not consider indirect cost and can therefore only draw an incomplete picture of efficiency [19-22, 54-57]. Therefore, it is critically important to consider HRWPL in future effectiveness and cost-effectiveness studies on antipsoriatic remedies. It is possible that savings from increased work productivity offset the comparatively high acquisition costs of biologicals. Evidence for a high efficiency of these agents would fundamentally influence the ongoing debate about their appropriate indication and target population.

An advantage of collecting data over the Internet is that participants are more likely to disclose private issues, which may result in data with higher validity compared to other methodologies $[58,59]$. In an Internet-recruited sample patients from all different geographical regions within the USA could easily participate. For both the Internet setting and the US healthcare system, significant ethnic and socioeconomic disparities regarding access exist [60-62].

As in other Internet-based studies, females and younger age groups appeared to be more likely and ethnic minorities less likely to participate [63]. Additionally, patients with psoriatic arthritis seem to be overrepresented in our sample. Here, misclassification by considering arthrosis or other joint diseases unrelated to psoriasis as psoriatic arthritis might be present. It cannot be excluded that patients who are more frustrated with their psoriasis and who have experienced more disease-related adverse working effects than the average psoriasis patient were more likely to take the time to respond to the advertisement and to complete the questionnaire so that recruitment bias cannot be excluded. This type of selection bias might have led to an overestimation of adverse working effects in patients suffering from psoriasis. Although recruitment bias is a general problem associated with surveys rather than a specific disadvantage of an Internetbased study, our results should be interpreted with caution. To overcome the problem of selection bias in future studies on HRWPL in psoriasis we recommend to draw a sufficiently large random sample from a source population in a clinical setting. In a survey on disease experiences, it is possible that participants tend to recall healthrelated problems better than experiences unrelated to the condition of interest. Therefore, an overestimation of the number of missed working time because of psoriasis cannot be ruled out. However, our qualitative finding that HRQL unlike clinical severity of psoriasis is related to 
HRWPL would neither be influenced by an overrepresentation of patients with more disease-related work limitations nor by differential recall bias with respect to the reason for missed working time.

A possible limitation of our study is the validity of the case definition. $96 \%$ of the study subjects reported that psoriasis was diagnosed by a physician. In another sample of psoriasis patients, Shikiar et al. [64] observed high construct validity of self-reported data both with respect to each other and to clinical assessments. Participants with lower HRWPL were less likely to have physician-diagnosed psoriasis so that a selection bias would underestimate the true HRWPL of psoriasis patients (table 1). In order to be applicable for the Internet setting, we used a modified version of the SAPASI with direct estimation of BSA involvement. The distribution in our sample of the mSAPASI was $9.5 \pm 8.9$, which is almost identical to the distribution of the SAPASI in its validation study [40]. Both WLQ and DLQI are instruments with adequate psychometric properties but have not been validated in an Internet setting before $[26,37]$. The observed distribution of the DLQI was highly similar to the distributions observed in other settings [37]. The accuracy of self-reported absence days has been established by Revicki et al. [65]. Overall, the quality of the collected data is considered high, particularly with regard to internal validity.

The mean WLQ output demands score we observed for psoriasis was similar to other chronic conditions including rheumatoid arthritis, osteoarthritis and dysthymia [28, 29, 31 . Both productivity loss due to health-related absenteeism and to presenteeism was about twice as high in patients with major depression compared to our sample [30].

The reader should not direct his attention primarily on the exact dollar cost of HRWPL in psoriasis patients. The message of the presented analysis is rather that the economic impact of HRWPL clearly exceeds the direct treatment-related costs [16]. With the formula we applied the annual costs of presenteeism and absenteeism are only approximations. The distributions of both presenteeism and absenteeism were positively skewed, but averages were used in the formula so that the true cost might be underestimated. On the other hand, because health-related rather than psoriasis-related productivity loss was assessed, comorbidity probably accounts for an overestimation of HRWPL solely attributable to psoriasis. The calculated cost assumes both generalizability of our productivity loss data and applicability of the average annual income data on the average employed psoriasis patient. Problems with these assumptions could have possibly biased our estimation in both directions. We further assumed that the unemployment rate in our study sample was generalizable to all psoriasis patients in the USA. However, unemployment was about 3 times more likely in our sample than in the US general population (16.3 vs. 5.5\%) [66]. This finding suggests an additional economic burden of psoriasis due to increased unemployment, which is not included in our calculation.

Our findings suggest that HRQL is an independent predictor of HRWPL. The weak crude association between HRWPL and clinical disease severity (mSAPASI) is probably confounded by HRQL impairment. Controlling for HRQL even involvement of the hands, one of the most obvious predictors of HRWPL, was only weakly associated with work productivity. This highlights that - at least from a societal health-economic perspective - strategies need to primarily focus on the patients' subjective wellbeing rather than on objective clinical signs.

\section{References}

1 Naldi L: Epidemiology of psoriasis. Curr Drug Targets Inflamm Allergy 2004;3:121-128.

2 Gelfand JM, Stern RS, Nijsten T, Feldman SR, Thomas J, Kist J, Rolstad T, Margolis DJ: The prevalence of psoriasis in African Americans: results from a population-based study. J Am Acad Dermatol 2005;52:23-26.

3 de Korte J, Sprangers MA, Mombers FM, Bos JD: Quality of life in patients with psoriasis: a systematic literature review. J Invest Dermatol Symp Proc 2004;9:140-147.
4 Krueger GG, Feldman SR, Camisa C, Duvic M, Elder JT, Gottlieb AB, Koo J, Krueger JG, Lebwohl M, Lowe N, Menter A, Morison WL, Prystowsky JH, Shupack JL, Taylor JR, Weinstein GD, Barton TL, Rolstad T, Day RM: Two considerations for patients with psoriasis and their clinicians: what defines mild, moderate, and severe psoriasis? What constitutes a clinically significant improvement when treating psoriasis? J Am Acad Dermatol 2000;43:281285.

5 Zachariae H, Zachariae R, Blomqvist K, Davidsson S, Molin L, Mork C, Sigurgeirsson B: Quality of life and prevalence of arthritis reported by 5,795 members of the Nordic Pso- riasis Associations. Data from the Nordic Quality of Life Study. Acta Derm Venereol 2002;82:108-113.

6 Markham T, Watson A, Rogers S: Adverse effects with long-term cyclosporin for severe psoriasis. Clin Exp Dermatol 2002;27:111-114.

7 Chaudhari U, Romano P, Mulcahy LD, Dooley LT, Baker DG, Gottlieb AB: Efficacy and safety of infliximab monotherapy for plaque-type psoriasis: a randomised trial. Lancet 2001; 357:1842-1847.

8 Ellis CN, Krueger GG: Treatment of chronic plaque psoriasis by selective targeting of memory effector T lymphocytes. N Engl J Med 2001;345:248-255. 
9 Gordon KB, Papp KA, Hamilton TK, Walicke PA, Dummer W, Li N, Bresnahan BW, Menter A: Efalizumab for patients with moderate to severe plaque psoriasis: a randomized controlled trial. JAMA 2003;290:3073-3080.

10 Leonardi CL, Powers JL, Matheson RT, Goffe BS, Zitnik R, Wang A, Gottlieb AB: Etanercept as monotherapy in patients with psoriasis. $\mathrm{N}$ Engl J Med 2003;349:2014-2022.

11 Stern RS: A promising step forward in psoriasis therapy. JAMA 2003;290:3133-3135.

12 Rich SJ: Considerations for assessing the cost of biologic agents in the treatment of psoriasis. J Manag Care Pharm 2004;10:S38-S41.

13 Feldman SR, Fleischer AB Jr, Reboussin DM, Rapp SR, Bradham DD, Exum ML, Clark AR: The economic impact of psoriasis increases with psoriasis severity. J Am Acad Dermatol 1997;37:564-569.

14 Galadari I, Rigel E, Lebwohl M: The cost of psoriasis treatment. J Eur Acad Dermatol Venereol 2001;15:290-291.

15 Heydendael VM, de Borgie CA, Spuls PI, Bossuyt PM, Bos JD, de Rie MA: The burden of psoriasis is not determined by disease severity only. J Invest Dermatol Symp Proc 2004; 9:131-135.

16 Javitz HS, Ward MM, Farber E, Nail L, Vallow SG: The direct cost of care for psoriasis and psoriatic arthritis in the United States. J Am Acad Dermatol 2002;46:850-860.

17 Jenner N, Campbell J, Plunkett A, Marks R: Cost of psoriasis: a study on the morbidity and financial effects of having psoriasis in Australia. Australas J Dermatol 2002;43:255-261.

18 Opmeer BC, Heydendael VM, de Borgie CA, Spuls PI, Bossuyt PM, Bos JD, de Rie MA: Costs of treatment in patients with moderate to severe plaque psoriasis: economic analysis in a randomized controlled comparison of methotrexate and cyclosporine. Arch Dermatol 2004; 140:685-690.

19 Russell LB, Gold MR, Siegel JE, Daniels N, Weinstein MC: The role of cost-effectiveness analysis in health and medicine. Panel on Cost-Effectiveness in Health and Medicine. JAMA 1996;276:1172-1177.

20 Siegel JE, Weinstein MC, Russell LB, Gold MR: Recommendations for reporting cost-effectiveness analyses. Panel on Cost-Effectiveness in Health and Medicine. JAMA 1996;276: 1339-1341.

21 Weinstein MC, Siegel JE, Gold MR, Kamlet MS, Russell LB: Recommendations of the Panel on Cost-Effectiveness in Health and Medicine. JAMA 1996;276:1253-1258.

22 Hannover Consensus Group: German recommendations for health care economic evaluation studies: revised version of the Hannover consensus. Med Klin (Munich) 2000;95:5255.

23 Drummond M, O'Brien B, Stoddart GL, Torrance G: Methods for the Economic Evaluation of Health Care Programmes. Toronto, Oxford Medical Publishers, 1998.
24 Gold MR, Siegel RG, Weinstein MC: Cost-Effectiveness in Health and Medicine. New York, Oxford University Press, 1996.

25 Hemp P: Presenteeism: at work - but out of it. Harv Bus Rev 2004;82:49-58, 155.

26 Prasad M, Wahlqvist P, Shikiar R, Shih YC: A review of self-report instruments measuring health-related work productivity: a patientreported outcomes perspective. Pharmacoeconomics 2004;22:225-244.

27 Lerner D, Amick BC III, Rogers WH, Malspeis S, Bungay K, Cynn D: The Work Limitations Questionnaire. Med Care 2001;39:7285.

28 Adler DA, Irish J, McLaughlin TJ, Perissinotto C, Chang H, Hood M, Lapitsky L, Rogers WH, Lerner D: The work impact of dysthymia in a primary care population. Gen Hosp Psychiatry 2004;26:269-276.

29 Lerner D, Reed JI, Massarotti E, Wester LM, Burke TA: The Work Limitations Questionnaire's validity and reliability among patients with osteoarthritis. J Clin Epidemiol 2002;55 197-208.

30 Lerner D, Adler DA, Chang H, Berndt ER, Irish JT, Lapitsky L, Hood MY, Reed J, Rogers WH: The clinical and occupational correlates of work productivity loss among employed patients with depression. J Occup Environ Med 2004;46:S46-S55.

31 Allaire S, Wolfe F, Niu J, Lavalley M, Michaud $\mathrm{K}$ : Work disability and its economic effect on 55- to 64-year-old adults with rheumatoid arthritis. Arthritis Rheum 2005;53:603-608.

32 Lerner D, Amick BC III, Lee JC, Rooney T, Rogers WH, Chang H, Berndt ER: Relationship of employee-reported work limitations to work productivity. Med Care 2003;41:649659.

33 US Department of Labor, Bureau of Labor Statistics: Quarterly census of employment and wages. http://www.bls.gov/cew/state2002.pdf. 2005.

34 US Census Bureau: Population by age, sex, race, and Hispanic or Latino origin for the United States: 2000 (PHC-T-9). Total population by age, race, and Hispanic or Latino origin for the United States: 2000. http://www. census.gov/population/cen2000/phc-t9/tab 01.pdf. 2005.

35 Finlay AY, Khan GK: Dermatology Life Quality Index (DLQI) - A simple practical measure for routine clinical use. Clin Exp Dermatol 1994;19:210-216

36 Khilij FA, Gonzalez M, Finlay AY: Clinical meaning of change in Dermatology Life Quality Index scores. Br J Dermatol 2002;147(sup$\mathrm{pl}$ 62):50.

37 Lewis V, Finlay AY: 10 years experience of the Dermatology Life Quality Index (DLQI). J Invest Dermatol Symp Proc 2004;9:169-180

38 Feldman SR, Fleischer AB Jr, Reboussin DM, Rapp SR, Exum ML, Clark AR, Nurre L: The self-administered Psoriasis Area and Severity Index is valid and reliable. J Invest Dermatol 1996;106:183-186
39 Feldman SR, Clark AR, Venkat AP, Fleischer AB Jr, Anderson RT, Rajagopalan R: The selfadministered Psoriasis Area and Severity Index provides an objective measure of psoriasis severity. Br J Dermatol 2005;152:382-383.

40 Fleischer AB Jr, Rapp SR, Reboussin DM, Vanarthos JC, Feldman SR: Patient measurement of psoriasis disease severity with a structured instrument. J Invest Dermatol 1994;102: 967-969.

41 Fleischer AB Jr, Feldman SR, Dekle CL: The SAPASI is valid and responsive to psoriasis disease severity changes in a multi-center clinical trial. J Dermatol 1999;26:210-215.

42 Sampogna F, Sera F, Mazzotti E, Pasquini P. Picardi A, Abeni D: Performance of the selfadministered Psoriasis Area and Severity Index in evaluating clinical and sociodemographic subgroups of patients with psoriasis. Arch Dermatol 2003;139:353-358.

43 Fredriksson T, Pettersson U: Severe psoriasis - Oral therapy with a new retinoid. Dermatologica 1978; 157:238-244.

44 Schmitt J, Wozel G: The Psoriasis Area and Severity Index is the adequate criterion to define severity in chronic plaque-type psoriasis. Dermatology 2005;210:194-199.

45 Stata Corporation: Stata 8 Reference Manual. College Station, Stata Corporation, 2003.

46 Stata Corporation: Stata Statistical Software: Release 8.0. College Station, Stata Corporation, 2002.

47 Feldman SR, Gordon KB, Bala M, Evans R, Li S, Dooley LT, Guzzo C, Patel K, Menter A, Gottlieb AB: Infliximab treatment results in significant improvement in the quality of life of patients with severe psoriasis: a doubleblind placebo-controlled trial. Br J Dermatol 2005;152:954-960.

48 Feldman SR, Menter A, Koo JY: Improved health-related quality of life following a randomized controlled trial of alefacept treatment in patients with chronic plaque psoriasis. Br J Dermatol 2004;150:317-326.

49 Krueger GG, Langley RG, Finlay AY, Griffiths CE, Woolley JM, Lalla D, Jahreis A: Patientreported outcomes of psoriasis improvement with etanercept therapy: results of a randomized phase III trial. Br J Dermatol 2005;153: 1192-1199.

50 Menter A, Kosinski M, Bresnahan BW, Papp KA, Ware JE Jr: Impact of efalizumab on psoriasis-specific patient-reported outcomes. Results from three randomized, placebo-controlled clinical trials of moderate to severe plaque psoriasis. J Drugs Dermatol 2004;3: 27-38.

51 Menter A: The effect of psoriasis on patients' quality of life and improvements associated with alefacept therapy. J Cutan Med Surg 2004;8(suppl 2):20-25.

52 Touw CR, Hakkaart-Van Roijen L, Verboom P, Paul C, Rutten FF, Finlay AY: Quality of life and clinical outcome in psoriasis patients using intermittent cyclosporin. Br J Dermatol 2001;144:967-972. 
53 Yelin E, Trupin L, Katz P, Lubeck D, Rush S, Wanke L: Association between etanercept use and employment outcomes among patients with rheumatoid arthritis. Arthritis Rheum 2003;48:3046-3054.

54 Stein KR, Pearce DJ, Feldman SR: The impact of biologics on the quality of life of psoriasis patients and the economics of psoriasis care. Semin Cutan Med Surg 2005;24:52-57.

55 Peeters P, Ortonne JP, Sitbon R, Guignard E: Cost-effectiveness of once-daily treatment with calcipotriol/betamethasone dipropionate followed by calcipotriol alone compared with tacalcitol in the treatment of psoriasis vulgaris. Dermatology 2005;211:139-145.

56 Ellis CN, Reiter KL, Bandekar RR, Fendrick AM: Cost-effectiveness comparison of therapy for psoriasis with a methotrexate-based regimen versus a rotation regimen of modified cyclosporine and methotrexate. J Am Acad Dermatol 2002;46:242-250.
57 Chen S, Shaheen A, Garber A: Cost-effectiveness and cost-benefit analysis of using methotrexate vs Goeckerman therapy for psoriasis: a pilot study. Arch Dermatol 1998;134:16021608.

58 Joinson A: Social desirability, anonymity, and Internet-based questionnaires. Behav Res Methods Instrum Comput 1999;31:433-438.

59 Durant LE, Carey MP, Schroder KE: Effects of anonymity, gender, and erotophilia on the quality of data obtained from self-reports of socially sensitive behaviors. J Behav Med 2002;25:438-467.

60 Kelley E, Moy E, Stryer D, Burstin H, Clancy C: The national healthcare quality and disparities reports: an overview. Med Care 2005;43: I3-I8.

61 Moy E, Dayton E, Clancy CM: Compiling the evidence: the National Healthcare Disparities Reports. Health Aff (Millwood) 2005;24:376387.
62 Baker L, Wagner TH, Singer S, Bundorf MK: Use of the Internet and e-mail for health care information: results from a national survey. JAMA 2003;289:2400-2406.

63 Houston TK, Cooper LA, Vu HT, Kahn J, Toser J, Ford DE: Screening the public for depression through the Internet. Psychiatr Serv 2001;52:362-367.

64 Shikiar R, Bresnahan BW, Stone SP, Thompson C, Koo J, Revicki DA: Validity and reliability of patient reported outcomes used in psoriasis: results from two randomized clinical trials. Health Qual Life Outcomes 2003;1: 53.

65 Revicki DA, Irwin D, Reblando J, Simon GE: The accuracy of self-reported disability days. Med Care 1994;32:401-404.

66 US Department of Labor, Bureau of Labor Statistics: Labor force statistics from the current population survey. http://www.bls.gov/cps/ home.htm. 2005. 